\title{
Prognostic value of tumor-infiltrating lymphocytes in patients with triple- negative breast cancer: a systematic review and meta-analysis
}

\author{
Guoxuan Gao, Zihan Wang, Xiang Qu* and Zhongtao Zhang
}

\begin{abstract}
Background: The objective of this systematic review and meta-analysis was to determine the prognostic value of total tumor-infiltrating lymphocytes (TILs) and subtypes of $\mathrm{TILS}\left(\mathrm{CD}^{+}, \mathrm{CD}^{+}\right.$, and $\left.\mathrm{FOXP3}^{+}\right)$in triple-negative breast cancer (TNBC).

Methods: A systematic search of the MEDLINE, EMBASE, and Web of Science databases was conducted to identified eligible articles published before August 2019. Study screening, data extraction, and risk of bias assessment were performed by two independent reviewers. Risk of bias on the study level was assessed using the ROBINS I tool and Quality in Prognosis Studies (QUIPS) tool. We performed a meta-analysis to obtain a pooled estimate of the prognostic role of TILs using Review Manager 5.3.

Results: In total, 37 studies were included in the final analysis. Compared to TNBC patients with low TIL levels, TNBC patients with high TIL levels showed a higher rate of pathological complete response (PCR) to treatment (odds ratio [OR] 2.14, 95\% confidence interval [CI] 1.43-3.19). With each 10\% increase in percentage of TILs, patients with TNBC had an increased pCR (OR 1.09, 95\% Cl 1.02-1.16). Compared to TNBC patients with low TIL levels, patients with high TIL levels had better overall survival (OS; hazard ratio [HR] 0.58, 95\% Cl 0.48-0.71) and diseasefree survival (DFS; HR 0.66, 95\% Cl 0.57-0.76). Additionally, with a continuous increase in TIL levels, patients with TNBC had improved OS (HR 0.90, 95\% Cl 0.87-0.93) and DFS (HR 0.92, 95\% Cl 0.90-0.95). A high CD4 ${ }^{+}$TIL level was associated with better OS (HR 0.49,95\% Cl 0.32-0.76) and DFS (HR 0.54, 95\% Cl 0.36-0.80). A high CD8 ${ }^{+}$TIL level was associated better DFS only (HR 0.55, 95\% Cl 0.38-0.81), as no statistical association was found with OS (HR 0.70, 95\% $\mathrm{Cl} 0.46-1.06)$. A high FOXP3 ${ }^{+}$TIL level also was associated with only DFS (HR 0.50, 95\% Cl 0.33-0.75) and not OS (HR 1.28, 95\% Cl 0.24-6.88).
\end{abstract}

Conclusions: TNBC with a high level of TILs showed better short-term and long-term prognoses. High levels of specific phenotypes of TILs $\left(\mathrm{CD}^{+}, \mathrm{CD}^{+}\right.$, and $\left.\mathrm{FOXP3}^{+}\right)$were predictive of a positive long-term prognosis for TNBC.

Keywords: Triple-negative breast cancer, Tumor-infiltrating lymphocytes, Prognosis, Meta-analysis

\footnotetext{
* Correspondence: cqx3968@sina.com

Department of General Surgery, Beijing Friendship Hospital, Capital Medical University, Beijing Key Laboratory of Cancer Invasion and Metastasis Research \& National Clinical Research Center for Digestive Diseases, 95 Yong-an Road, Beijing 100050, China
}

(c) The Author(s). 2020 Open Access This article is licensed under a Creative Commons Attribution 4.0 International License, which permits use, sharing, adaptation, distribution and reproduction in any medium or format, as long as you give appropriate credit to the original author(s) and the source, provide a link to the Creative Commons licence, and indicate if changes were made. The images or other third party material in this article are included in the article's Creative Commons licence, unless indicated otherwise in a credit line to the material. If material is not included in the article's Creative Commons licence and your intended use is not permitted by statutory regulation or exceeds the permitted use, you will need to obtain permission directly from the copyright holder. To view a copy of this licence, visit http://creativecommons.org/licenses/by/4.0/ The Creative Commons Public Domain Dedication waiver (http://creativecommons.org/publicdomain/zero/1.0/) applies to the data made available in this article, unless otherwise stated in a credit line to the data. 


\section{Background}

Triple-negative breast cancer (TNBC) is the term used to describe breast cancer cases that lack expression of estrogen receptor (ER), human epidermal growth factor receptor-2 (HER2), and progesterone receptor (PR) [1]. TNBC is characterized by a poor prognosis, and accordingly, the 5-year survival rate is only around 60\% [2]. As the malignancy of breast cancer depends not only on its genetic abnormalities and biological characteristics but also on interactions between the cancer cells and their microenvironment, it is vital to understand the tumor microenvironment [3].

The microenvironment of breast cancer contains a variety of cell types, including tumor-infiltrating lymphocytes (TILs). Accumulating evidence indicates that TILs play essential roles in carcinogenesis and cancer progression [4]. Furthermore, interleukin (IL)-6 and IL-8 secreted by some subtypes of lymphocytes can generate a positive feedback loop between the immune microenvironment and tumor cells [5]. According to the results of a meta-analysis in 2014, the level of TILs was positively associated with a the prognosis of TNBC [6]. However, various subtypes of TILs have both inhibitory and stimulatory effects on the prognosis and progression of breast cancer. The $\mathrm{CD}^{+} \mathrm{T}$ cells and $\mathrm{CD}^{+} \mathrm{T}$ cells (primary effector TIL subtypes) have been linked to a better response to systemic treatment in breast cancer [7, 8]. On the contrary, $\mathrm{FOXP3}^{+}$T-cell infiltration was found to predict a worse prognosis via the mediation of tumor immune escape $[9,10]$. Because TNBC has unique clinicopathological and immunohistochemical features, determining the clinical associations of the total TIL count or the levels of specific subtypes of TILs in TNBC can improve our ability to predict the prognostic pattern and treatment response for TNBC.

The objective of the present systematic review and meta-analysis was to determine the prognostic roles of the total TILs or the levels of subtypes of TILs $\left(\mathrm{CD} 4^{+}\right.$, $\mathrm{CD}^{+}$, and $\mathrm{FOXP3}^{+}$) in $\mathrm{TNBC}$.

\section{Methods}

The present systematic review and meta-analysis were conducted following the requirements of the Preferred Reporting Items for Systematic Reviews and MetaAnalyses (PRISMA) statement [11].

\section{Search strategy and study selection}

A systematic literature search was conducted using the MEDLINE, EMBASE, and Web of Science databases to identify eligible articles published before August 2019. The keywords used for the literature search included triple-negative breast cancer (TNBC), tumor-infiltrating lymphocytes (TILs), prognosis, and survival. Review and meta-analysis articles were scanned for additional relevant studies. The literature search strategies are outlined in Additional file 1.

\section{Outcome definitions}

Pathological complete response (pCR) was defined as the absence of all invasive disease cells and lymph node metastasis [12]. Overall survival (OS) was defined as the period from the date of TNBC diagnosis to the time of death with any cause [13]. Disease-free survival (DFS) was defined as the period from the start of treatment to the first recurrence, or to death without any type of relapse [13].

\section{Inclusion and exclusion criteria}

The inclusion criteria were the following: (1) paper written in English, (2) study population or study sub-group consisted of patients with TNBC, (3) the relationships between TIL levels and short-term prognosis (i.e., pCR) and long-term prognosis (i.e., OS and DFS) were investigated, (4) original studies without restriction in study design, (5) studies containing enough data to estimate the effects (i.e., hazard ratios [HRs] and corresponding 95\% confidence intervals [CIs] for OS or DFS, and odds ratios [ORs] and corresponding 95\% CIs for pCR). The exclusion criteria were the following: (1) reviews, commentaries, editorials, protocols, case reports, qualitative research, or letters; (2) duplicate publications; and (3) full text not published in English, and (4) studies without usable data.

\section{Study selection and quality assessment}

Title-abstract screening was performed first to determine eligibility by two independent reviewers. Full-text articles that passed the first stage screening were downloaded for further review according to the inclusion and exclusion criteria. Disagreements were resolved by consultation with a third author or by joint discussion.

As no randomized controlled trial was found, we assessed the risk of bias using an approach based on the ROBINS I tool [14] and the Quality In Prognosis Studies (QUIPS) tool [15]. The risk of bias assessment was conducted by two reviewers independently.

\section{Data extraction}

We extracted data from the included studies using a pilot-tested data extraction form. We extracted the following data for this review: (1) first author and publication year, (2) country in which study was conducted, (3) study design, (4) participant details, (5) duration of follow-up, (6) choice of cut-off scores for defining positive TILs, (7) TIL category, (8) TIL measurement details (category or continuous). The definition of high/low TIL level were attributed to the original papers. (9) adjusted HRs with 95\% CIs for OS and/or DFS (univariable HRs 
were recorded only if adjusted HRs were not available), and (10) adjusted ORs with 95\% CIs (or accurate event numbers) for pCR (univariable ORs were recorded only if adjusted ORs were not available).

\section{Statistical analysis}

We performed meta-analyses to obtain a pooled estimate of the prognostic role of TILs using RevMan 5.3. Category software, and continuous TILs were estimated separately to decrease the heterogeneity. The results were expressed as HR (95\% CI) for OS and DFS and by OR $(95 \% \mathrm{CI})$ as calculated by Review Manager 5.3 [16]. A $P$-value less than 0.05 was set as indicative of statistical significance. Between-study heterogeneity was measured using the Higgins $\mathrm{I}^{2}$ statistic and Cochrane's Q test $\left(P<0.10\right.$ or $\mathrm{I}^{2}>50 \%$ was considered indicative of statistically significant heterogeneity) [17]. A random effects model (Der Simonian and Laird method) was applied if heterogeneity was present. However, the fixedeffect model was used in the absence of between-study heterogeneity $\left(P>0.10\right.$ or $\left.\mathrm{I}^{2}<50 \%\right)$. We performed subgroup analyses according to different subtypes of TILs as a sensitivity analysis to confirm the robustness of our results. Funnel plots were drafted for each meta-analysis to assess the potential publication bias.

\section{Results}

Search results and study characteristics

A total of 3194 articles were selected through searching the chosen electronic databases, and an additional 5 records were identified by cross-checking the bibliographies of retrieved meta-analysis or relevant reviews. After exclusion of duplicates, we screened the titles and abstracts and identified 46 articles for full-text review. We eliminated 9 papers according to the inclusion/exclusion criteria. Ultimately, 37 papers were included in the final analysis (Fig. 1) [7, 18-53].

The basic characteristics and target outcomes extracted from the included studies are listed in Table 1. All included articles $(n=37)$ were full-reported retrospective cohort studies. The studies were conducted in the United States $(18.9 \%, 7 / 37)$, Japan $(16.2 \%, 6 / 37)$, South Korea $(16.2 \%, 6 / 37)$, China $(8.1 \%, 3 / 37)$, France (8.1\%, 3/37), Italy $(3.4 \%, 2 / 37)$, Singapore $(3.4 \%, 2 / 37)$, Germany (5.4\%, 2/37), Australia (2.7\%, 1/37), Peru (2.7\%, $1 / 37)$, Spain $(2.7 \%, 1 / 37)$, Canada $(2.7 \%, 1 / 37)$, Ireland

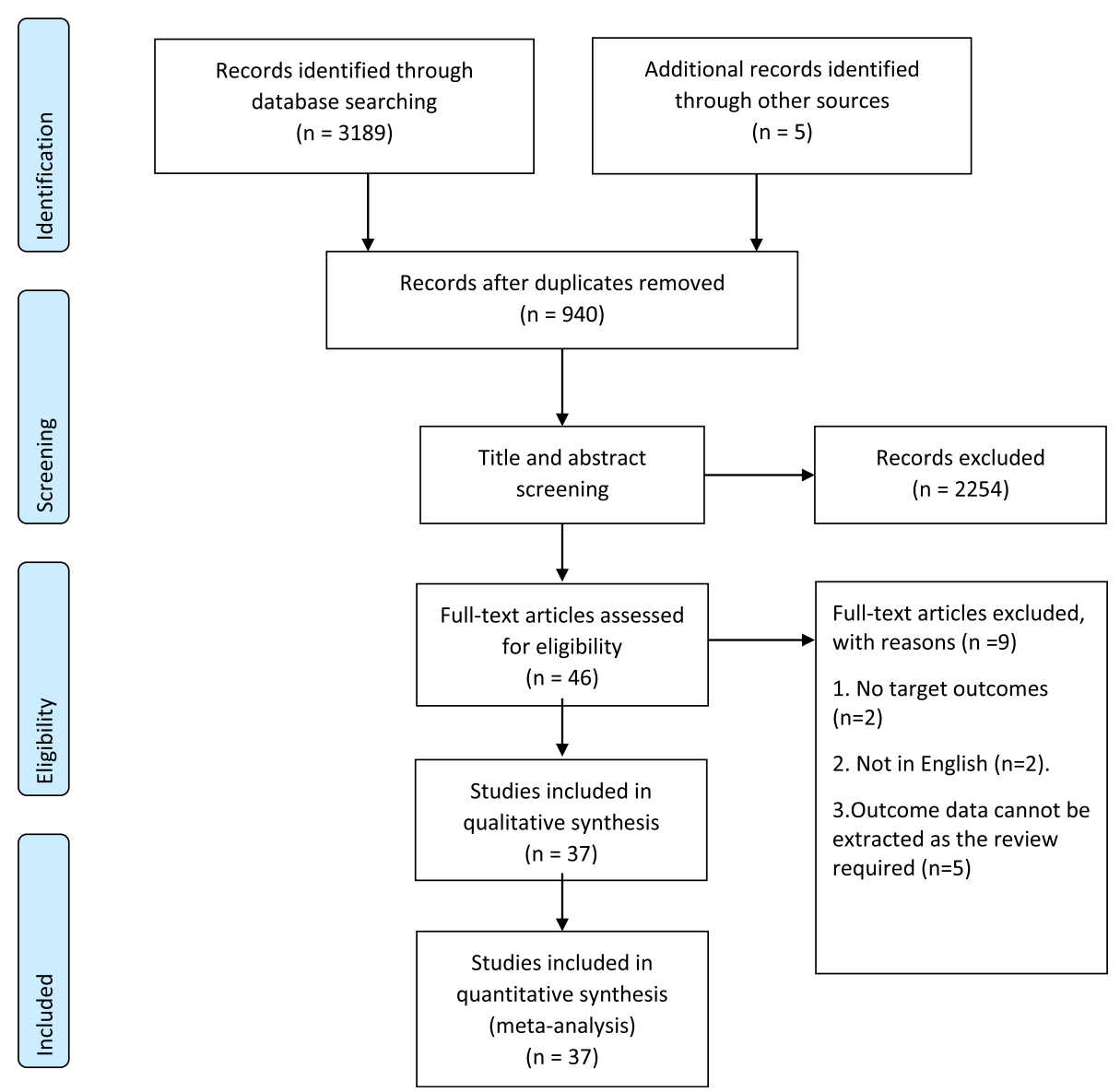

Fig. 1 PRISMA flow diagram detailing the search strategy and results [11] 


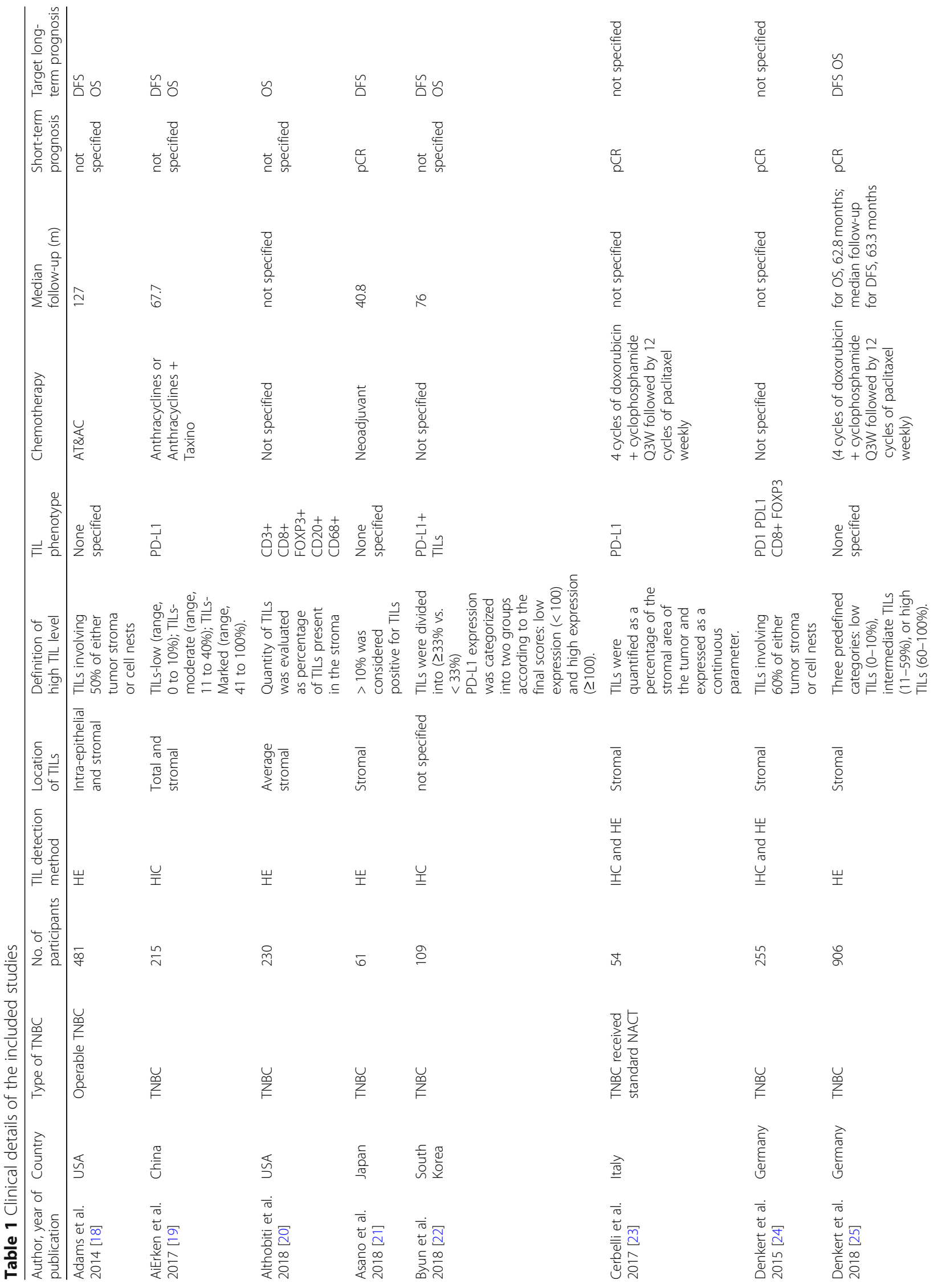




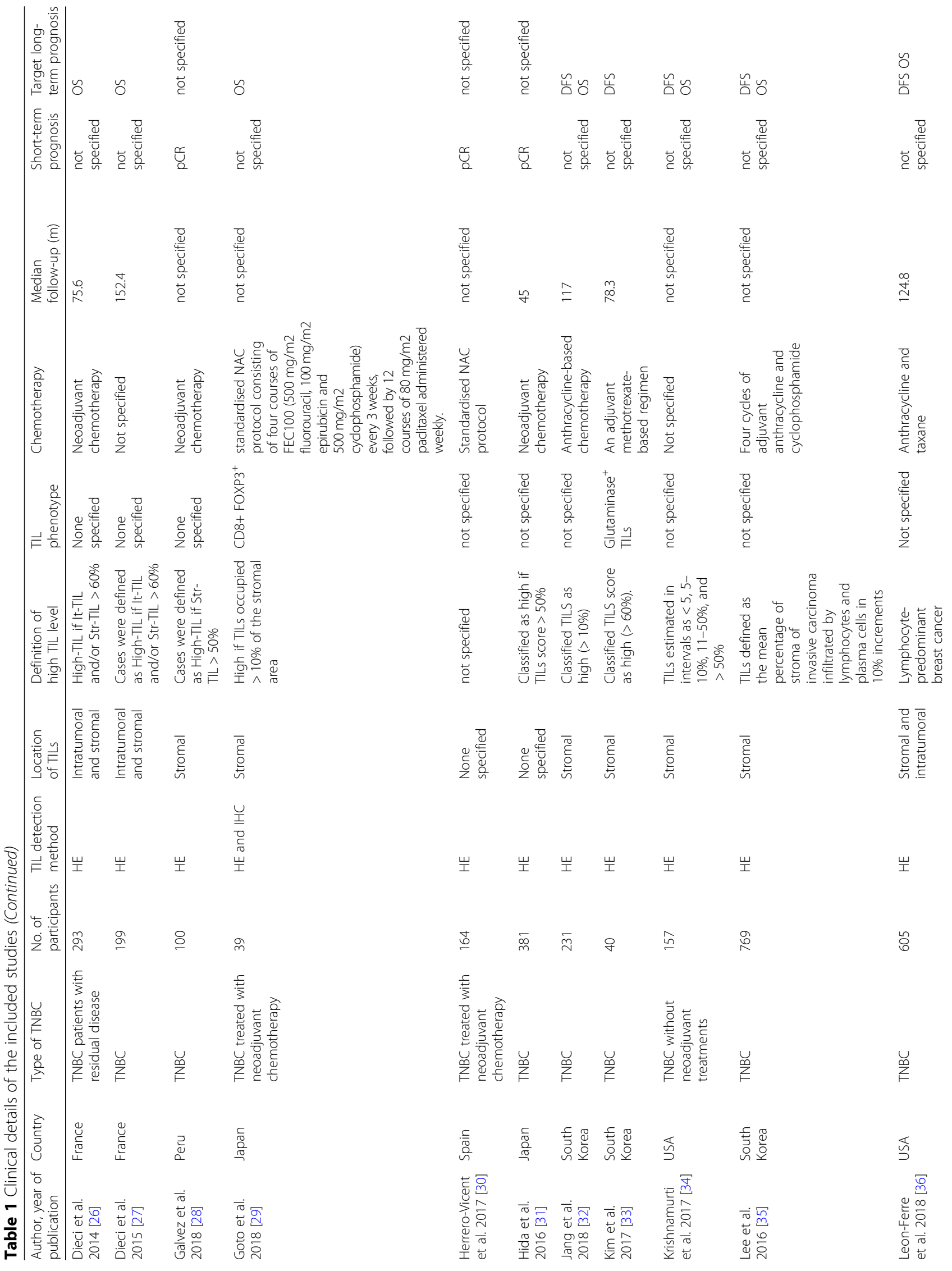




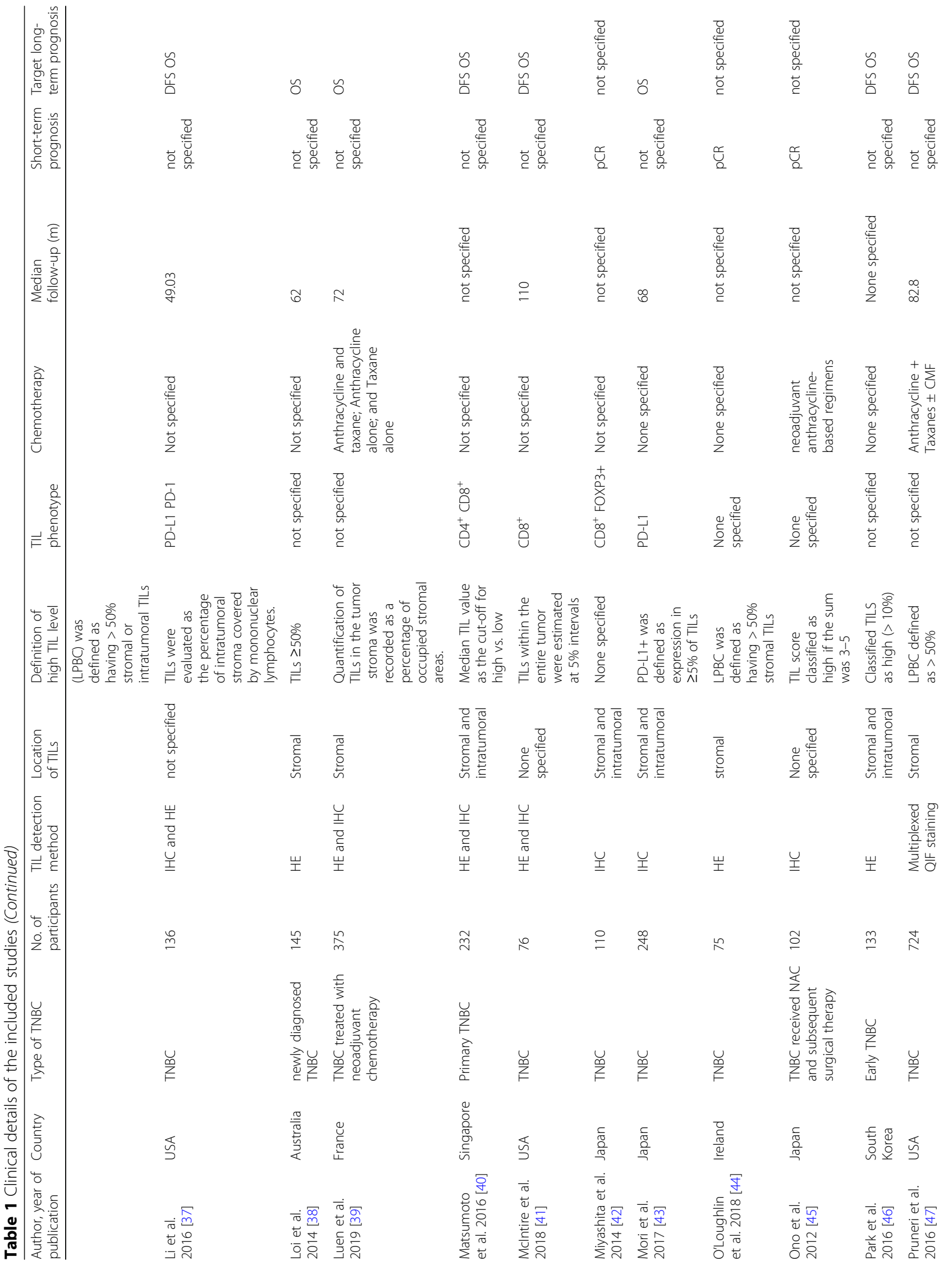




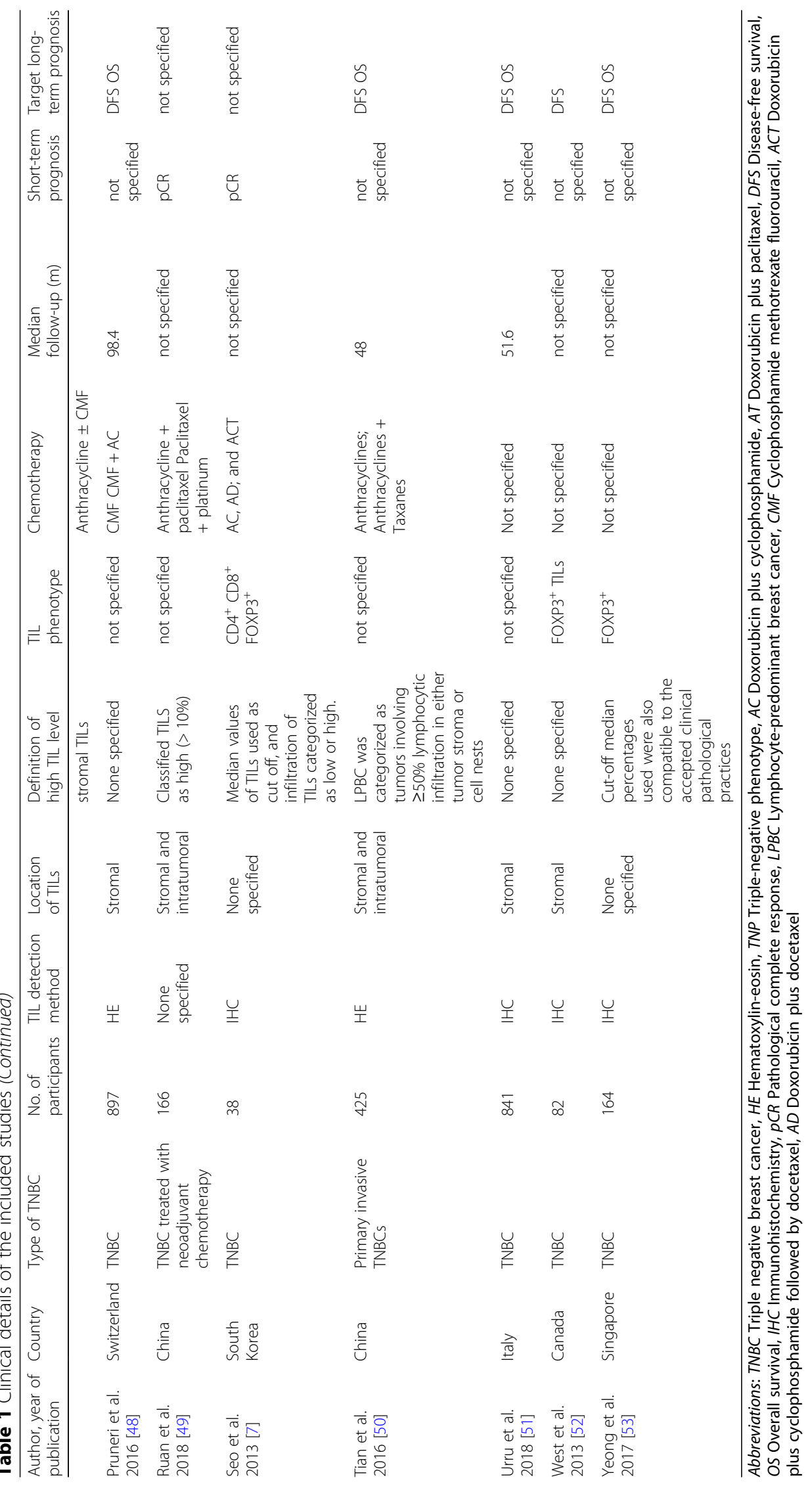


(2.7\%, 1/37), and Switzerland (2.7\%, 1/37). The population targeted was patients with TNBC. Eleven studies $(29.7 \%, 11 / 37)$ provided evidence of the prognostic value of TILs for short-term outcomes (pCR), and five (75.7\%, 28/37) provided evidence of the prognostic values of TILs for long-term outcomes (OS and/or DFS). The details of data extraction are presented in Additional file 2.

\section{TILs and $\mathrm{pCR}$}

From the 11 studies demonstrating the prognostic value of TILs for pCR among TNBC patients, the results showed that upregulation of TILs predicted a higher pCR rate. The pooled ORs were 2.14 (95\% CI, 1.433.19) for TIL level (high vs. low) and 1.09 (95\% CI, 1.021.16) for continuous TILs (10\% increase in TIL level). When stratified by the TIL phenotypes of $\mathrm{CD} 4^{+}, \mathrm{CD} 8^{+}$, and $\mathrm{FOXP3}^{+}$, no statistical differences in $\mathrm{pCR}$ were found in the subgroup analysis. The details pooled results are presented in Fig. 2.

\section{TILs and OS}

A total of 24 studies supported the prognostic value of TILs for OS in TNBC patients. The results showed upregulation of TILs predicted a better OS. The pooled HRs were 0.58 (95\% CI, 0.48-0.71) for total TIL level (high vs. low) and 0.90 (95\% CI, 0.87-0.93) for continuous TILs (Fig. 3).

From subgroup analyses according to TIL phenotype (high vs. low), the HRs were 0.49 (95\% CI, 0.32-0.76), 0.70 (95\% CI, 0.46-1.06), and 1.28 (95\% CI, 0.24-6.88) for $\mathrm{CD}^{+}{ }^{+}$TILs, $\mathrm{CD}^{+}$TILs, and FOXP3 ${ }^{+}$TILs, respectively (Fig. 3a). Subgroup analyses according to the change in TIL level (continuous) returned HRs of 0.50 (95\% CI, 0.28-0.89) and 1.80 (95\% CI, 0.50-6.48) for $\mathrm{CD} 8{ }^{+}$TILs and FOXP3 ${ }^{+}$TILs, respectively (Fig. 3b).

\section{TILs and DFS}

A total of 20 studies supported the prognostic value of TILs for DFS in TNBC patients. The results showed upregulation of TILs predicted better DFS, with pooled HRs of 0.66 (95\% CI, 0.57-0.76) for TIL level (high vs. low) and 0.92 (95\% CI, 0.90-0.95) for continuous TILs (Fig. 4).

From subgroup analyses according to TIL phenotype (high vs. low), the HRs were 0.54 (95\% CI, 0.36-0.80), 0.55 (95\% CI, 0.38-0.81), and 0.50 (95\% CI, 0.33-0.75) for $\mathrm{CD}^{+}{ }^{+}$TILs, $\mathrm{CD}^{+}$TILs, and FOXP3 ${ }^{+}$TILs, respectively (Fig. 4a).

Subgroup analyses according to the change in TIL level (continuous) returned HRs of 0.93 (95\% CI, $0.90-0.96), 0.70$ (95\% CI, 0.39-1.27), and 0.41 (95\% CI, $0.21-0.80$ ) for a $10 \%$ increase in TILs, continuous TILs, and a $5 \%$ increase in TILs of each subgroup, respectively (Fig. 4b).

\section{Risk of bias in included studies}

We evaluated the risk of bias for all included studies $(n=37)$. We found the main sources of bias were related to missing data, TIL measurement and confounding controls. Most of the missing data due to that not all the available patients were included in the final analysis as the information was not complete (participants were excluded due to missing data). Figure 5a shows the risk of bias assessments for each cohort. Evaluations for each domain across full reported studies are shown in Fig. 5b.

\section{Publication bias}

Funnel plot analysis did not indicate apparent publication bias affecting the HRs for DFS and OS or the ORs for pCR in the included studies (Fig. 6).

\section{Discussion}

As TNBC is a poor prognostic subtype of breast cancer, it is important to identify biomarkers that can rigorously predict its prognosis. The present review and meta-analysis synthesized 37 studies to evaluate the association between TIL levels, both total and specific subtypes, and prognosis in TNBC patients. Our findings indicate that a high TIL level in TNBC significantly increases the likelihood of $\mathrm{pCR}$ and improves DFS and OS.

In the present study, we used pCR as the indicator of short-term prognosis for patients with TNBC. Previous studies reported that higher TIL levels predict a better response to chemotherapy in patients with breast cancer [54-56]. According to our pooled results, compared to TNBC patients with low TIL levels, TNBC patients with high TIL levels had a higher rate of pCR to treatment (OR 2.14, 95\% CI 1.43-3.19). Moreover, with each 10\% increase in TIL level, patients with TNBC had an increased $\mathrm{PCR}$ rate (OR 1.09, 95\% CI 1.02-1.16). A potential explanation for these findings is the influence of TILs to tumor immunosurveillance and tumor immunosuppression [57]. In addition, the treatment used in the included articles was inconsistent. However, no significant $\mathrm{pCR}$ improvement was observed for high levels of the $\mathrm{CD}^{+}, \mathrm{CD}^{+}$, and $\mathrm{FOXP}^{+}$TIL subgroups. This may due to the limited amount of data available for these subgroups.

The indicators of long-term prognosis in this study were OS and DFS. According to our pooled results, compared to TNBC patients with low TIL levels, patients with high TIL levels showed better OS (HR 0.58, 95\% CI 0.48-0.71) and DFS (HR 0.66, 95\% CI $0.57-0.76)$. Additionally, with a continuously increasing TIL levels, patients with TNBC had improved OS (HR 0.90, 95\% CI 0.87-0.93) and DFS (HR 0.92, 95\% CI 0.90-0.95). This finding is consistent with previous conclusions $[3,9,25,58,59]$. Our results indicate 


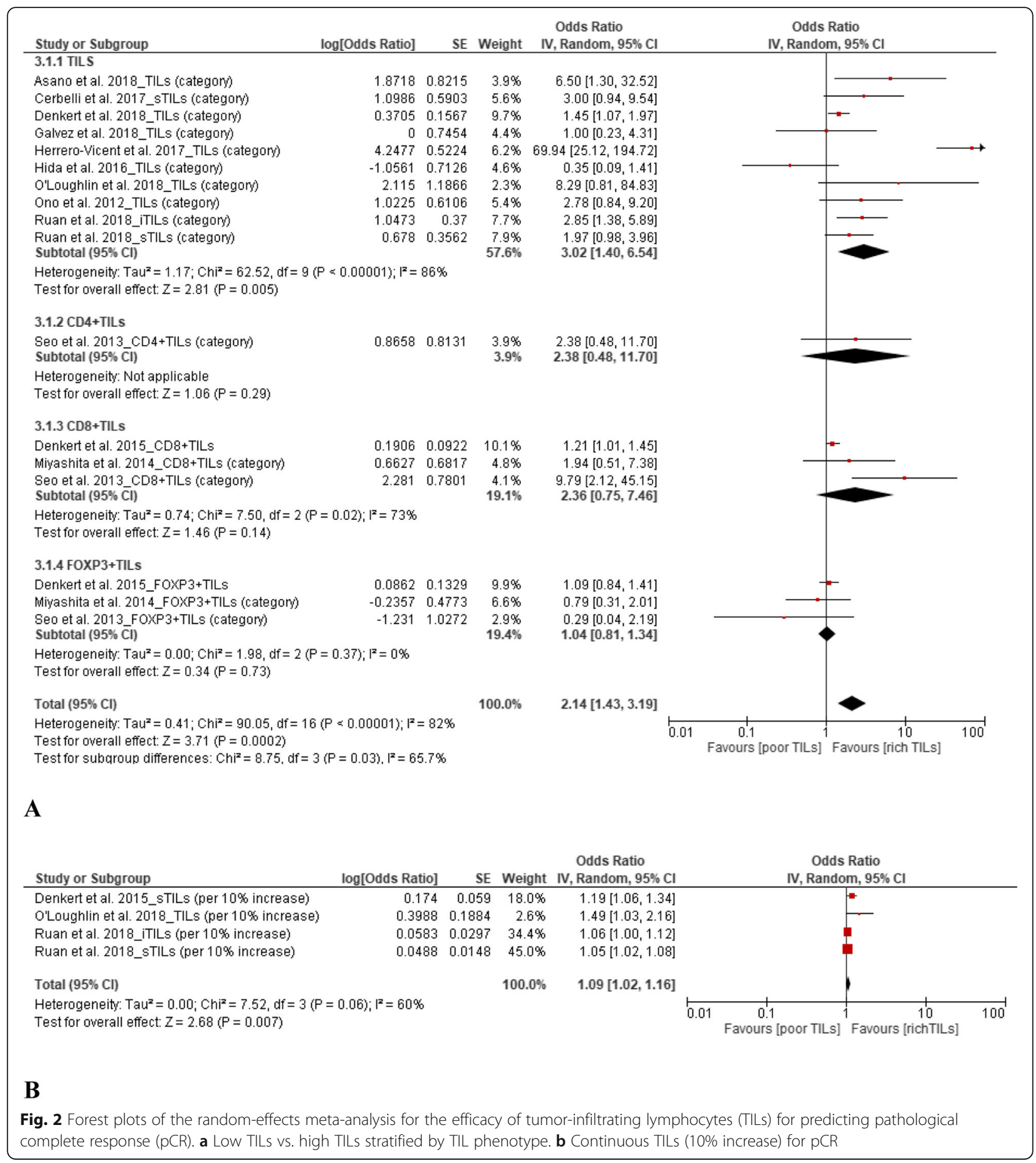

that a high level of TILs is a positive predictor for the prognosis of patients with TNBC.

The CD4 ${ }^{+}$TIL subgroup (high vs. low) showed a better OS (HR 0.49, 95\%CI 0.32-0.76) and DFS (HR 0.54, 95\%CI 0.36-0.80), and the CD8 ${ }^{+}$TIL subgroup (high vs. low) showed a better DFS only (HR 0.55, 95\% CI 0.380.81). Nevertheless, the pooled results indicated $\mathrm{CD}_{4}^{+}$
TILs and $\mathrm{CD}^{+}$TILs were positive predictors for longterm prognosis in TNBC. This is consistent with previous meta-analysis results [6]. The FOXP3 ${ }^{+}$TIL subgroup (high vs. low) also showed only better DFS (HR 0.50, 95\% CI 0.33-0.75), with no statistical association with OS (HR 1.28, 95\% CI 0.24-6.88). This finding for FOXP3 $^{+}$TILs is opposite to that of previous meta- 


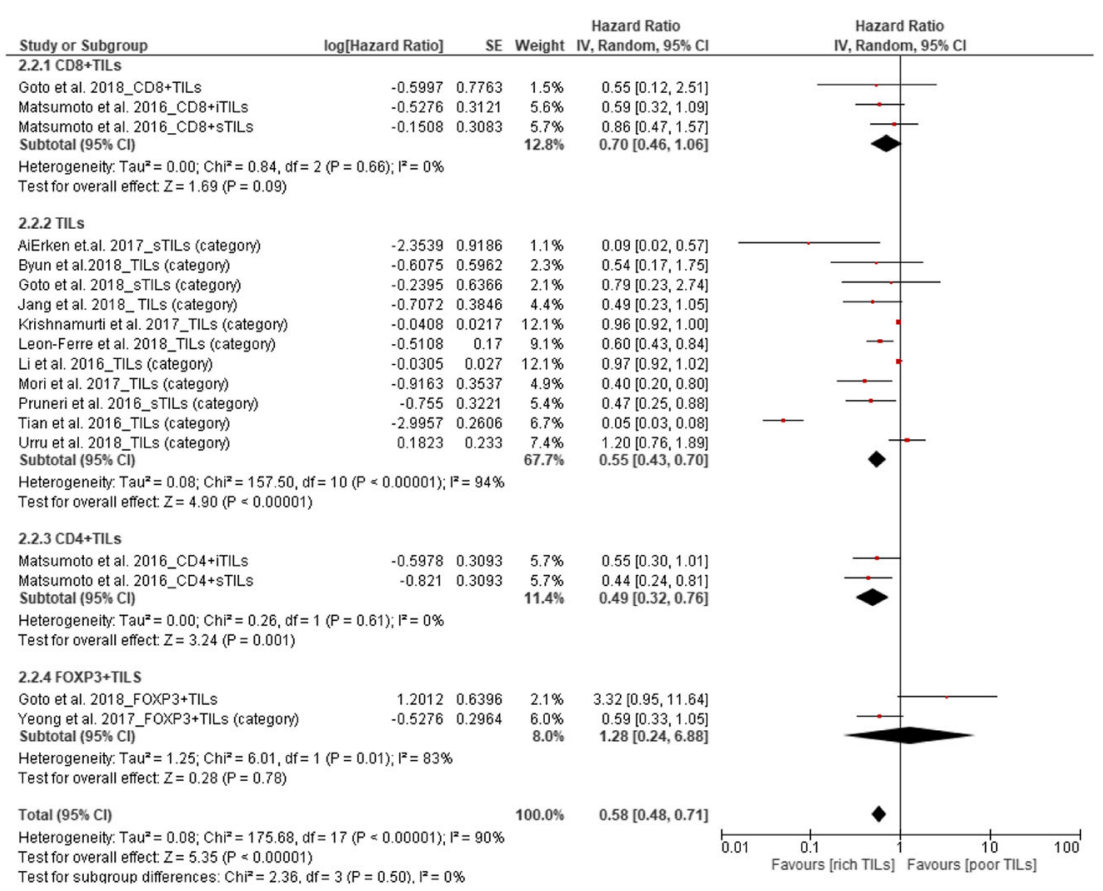

A

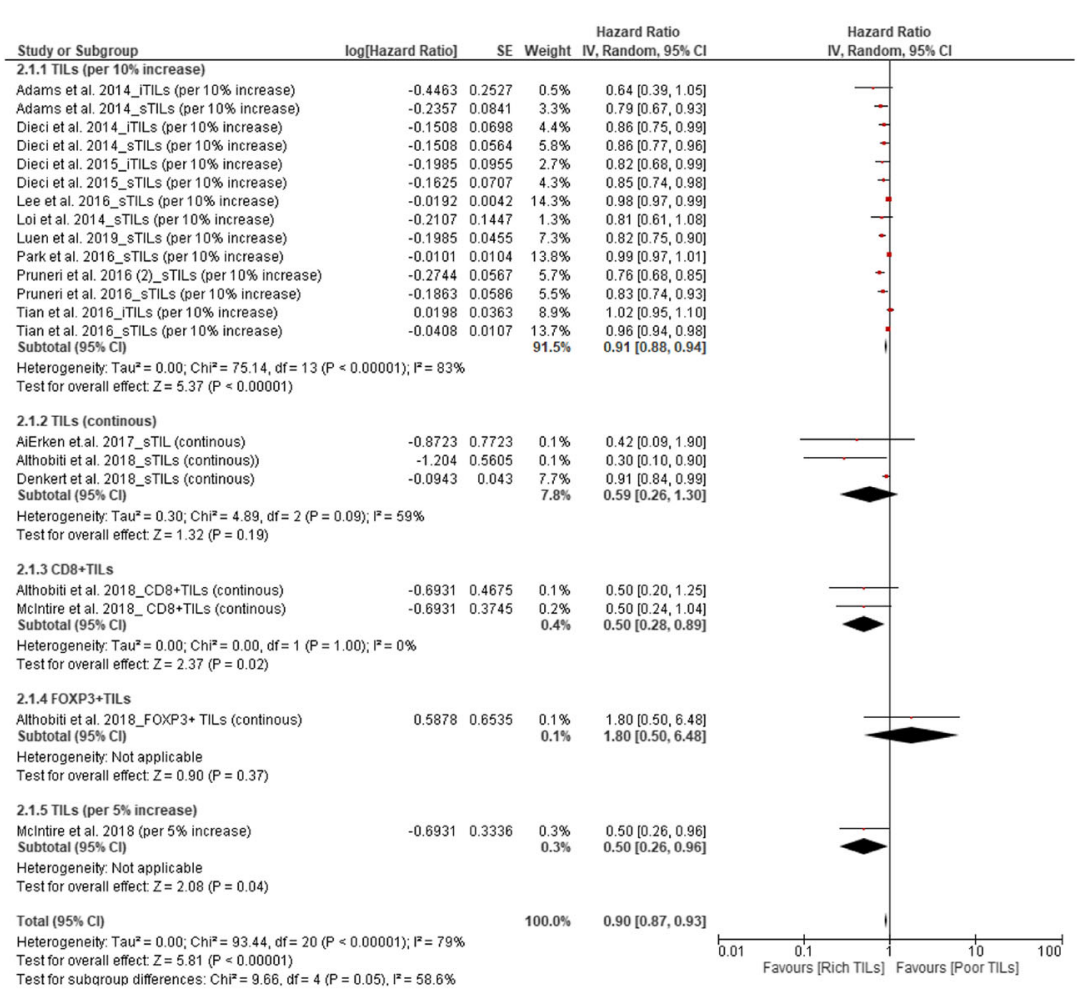

B

Fig. 3 Forest plots of the random-effects meta-analysis for the efficacy of tumor-infiltrating lymphocytes (TILs) for overall survival (OS). a Low TILS vs. high TILs stratified by TIL phenotypes. b TILs stratified by continuous TILs, 5\% increase in TILs, 10\% increase in TILs, and phenotypes 


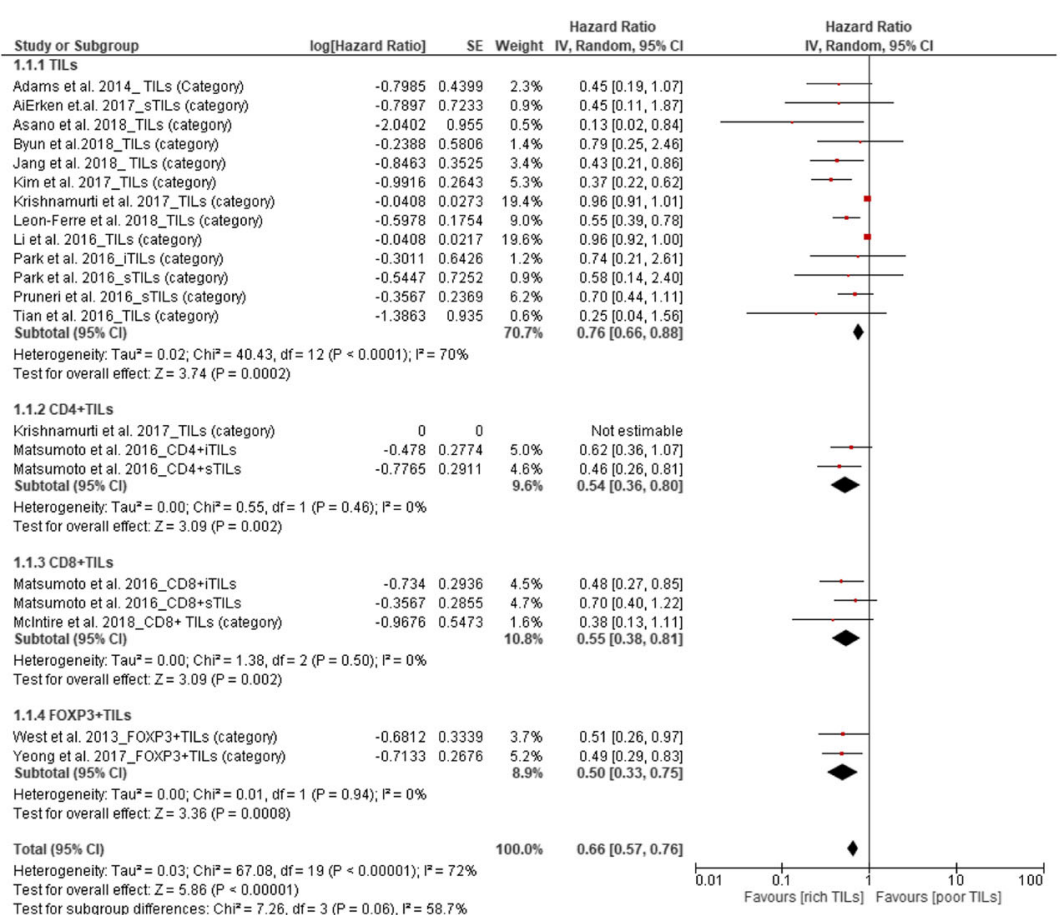

\section{A}

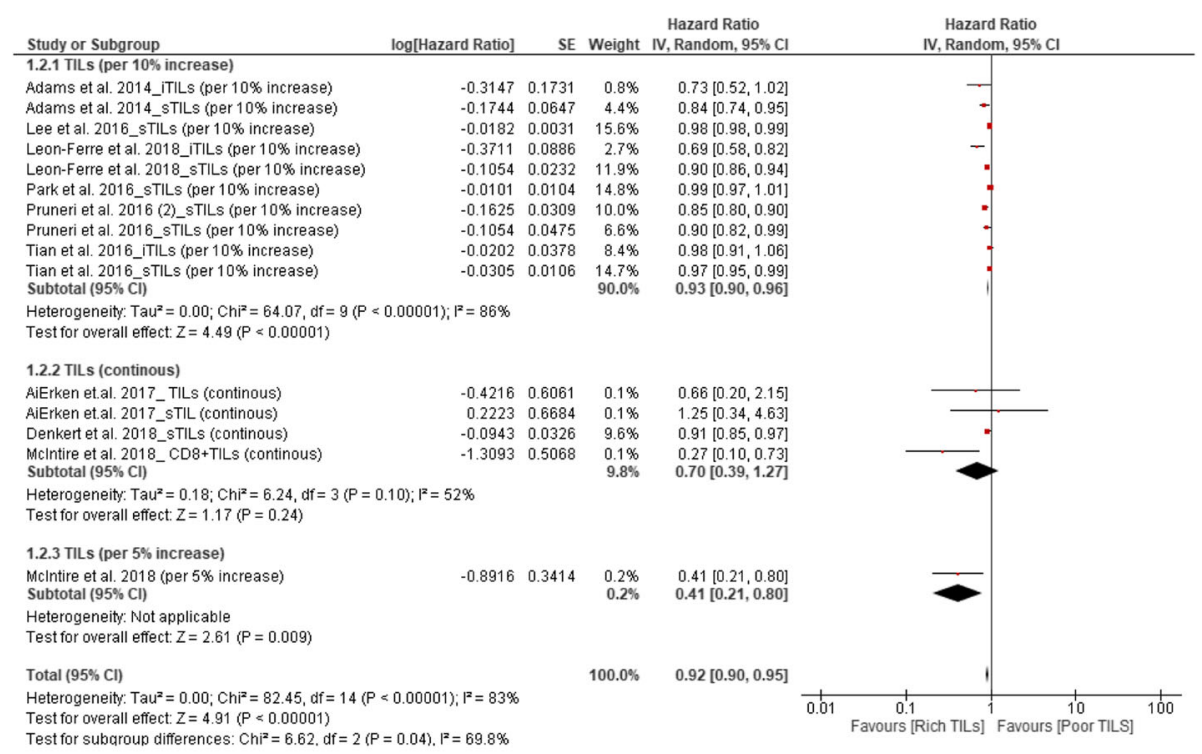

\section{B}

Fig. 4 Forest plots of the random-effects meta-analysis for the efficacy of tumor-infiltrating lymphocytes (TILs) for disease-free survival (DFS). a Low TILs vs. high TILs stratified by TIL phenotype. b TILs stratified by continuous TILs, 5\% increase in TILs, and 10\% increase in TILs

analyses [3, 6], and the reason for this inconsistency is unclear. More studies of the association of $\mathrm{FOXP}^{+}$TILs with the prognosis of TNBC are needed.

To our best knowledge, this was the first meta-analysis to pool the prognostic results for categorical TIL level and continuous TILs separately. Therefore, from the results, we can definitively conclude that a higher density of TILs corresponds to a better prognosis for TNBC. Our study does have some limitations. First, all included studies were retrospective cohort studies, with risks of 


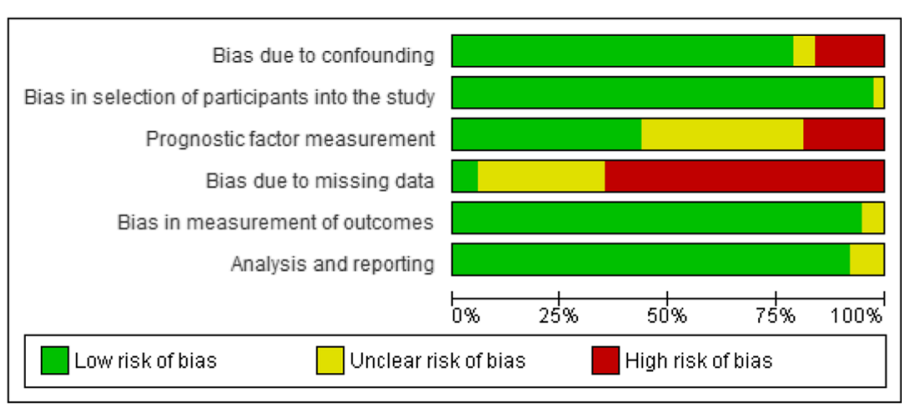

A

\begin{tabular}{|c|c|c|c|c|c|c|}
\hline & 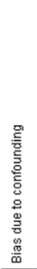 & 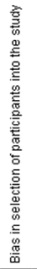 & 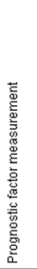 & 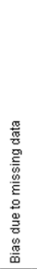 & 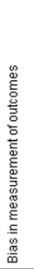 & 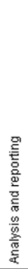 \\
\hline Adams et al. 2014 & \begin{tabular}{|l|l}
+ & \\
\end{tabular} & $\odot$ & \begin{tabular}{|l|l|}
$?$ \\
\end{tabular} & e & (๑) & 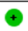 \\
\hline Ailerken et al. 2017 & \begin{tabular}{|l|}
+ \\
\end{tabular} & (๑) & + & 3 & (†) & 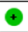 \\
\hline Althobiti et al. 2018 & \begin{tabular}{|l|l} 
(†) \\
\end{tabular} & (†) & (†) & ? & (†) & (†) \\
\hline Asano et al. 2018 & - & + & $\odot$ & $?$ & $?$ & $?$ \\
\hline Byun et al. 2018 & \begin{tabular}{|c|}
+ \\
\end{tabular} & (๑) & • & (๑) & (†) & (†) \\
\hline Cerbelli et al. 2017 & - & + & ๑ & 3 & $\odot$ & $?$ \\
\hline Denkert et al. 2015 & \begin{tabular}{|l|}
3 \\
\end{tabular} & + & • & 3 & ๑) & + \\
\hline Denkert et al. 2018 & $\odot$ & $\odot$ & \begin{tabular}{|l|l}
$?$ \\
\end{tabular} & ? & $\odot$ & 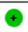 \\
\hline Dieci et al. 2014 & \begin{tabular}{|l|}
3 \\
\end{tabular} & (๑) & \begin{tabular}{l|l}
$?$ \\
\end{tabular} & 3 & (†) & ๑ \\
\hline Dieci et al. 2015 & (๑) & $?$ & \begin{tabular}{|l|l}
$?$ \\
\end{tabular} & $?$ & (๑) & ๑) \\
\hline Galvez et al. 2018 & అ & $\odot$ & \begin{tabular}{|l|l}
$?$ \\
\end{tabular} & (๑) & $\odot$ & $\odot$ \\
\hline Goto et al. 2018 & (๑) & (๑) & 3 & e & $?$ & $\odot$ \\
\hline Herrero-Vicent et al. 2017 & అ & + & ๑) & e & (†) & 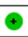 \\
\hline Hida et al. 2016 & - & + & $\odot$ & $\theta$ & 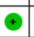 & $\odot$ \\
\hline Jang et al. 2018 & \begin{tabular}{|c|}
+ \\
\end{tabular} & + & \begin{tabular}{l|l}
$?$ \\
\end{tabular} & ○ & 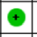 & + \\
\hline Kim et al. 2017 & \begin{tabular}{|c|}
+ \\
\end{tabular} & () & \begin{tabular}{l|l}
$?$ \\
\end{tabular} & ? & (๑) & $?$ \\
\hline Krishnamurti et al. 2017 & \begin{tabular}{|c|} 
\\
\end{tabular} & • & ○ & $?$ & () & (†) \\
\hline Lee et al. 2016 & (๑) & $\odot$ & \begin{tabular}{|l|l}
3 & \\
\end{tabular} & e & (๑) & ๑ \\
\hline Leon-Ferre et al. 2018 & \begin{tabular}{|c|}
+ \\
\end{tabular} & $\odot$ & • & $\theta$ & ( & • \\
\hline Li et al. 2016 & (๑) & $\odot$ & \begin{tabular}{|l|l}
$?$ \\
\end{tabular} & ? & (๑) & (†) \\
\hline Loi et al. 2014 & \begin{tabular}{|c|}
+ \\
\end{tabular} & + & - & - & 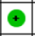 & + \\
\hline Luen et al. 2019 & (๑) & $\oplus$ & - & $\theta$ & ๑) & ๑ \\
\hline Matsumoto et al. 2016 & (๑) & ๑ & - & $\theta$ & (†) & (†) \\
\hline McIntire et al. 2018 & (๑) & + & • & $\theta$ & $\odot$ & + \\
\hline Mirashita et al. 2014 & (๑) & (๑) & \begin{tabular}{l|l}
$?$ & \\
\end{tabular} & e & ๑) & ๑ \\
\hline Mori et al. 2017 & \begin{tabular}{|l|} 
( \\
\end{tabular} & (๑) & ๑) & $\theta$ & (๑) & + \\
\hline O'Loughlin et al. 2018 & (๑) & (๑) & • & 3 & (๑) & ๑ \\
\hline Ono et al. 2012 & \begin{tabular}{|c|}
+ \\
\end{tabular} & ๑ & - & e & ๑) & ๑ \\
\hline Park et al. 2016 & \begin{tabular}{|l|}
+ \\
\end{tabular} & + & ๑) & e & (๑) & ๑) \\
\hline Pruneri et al. 2016 & (4) & (†) & ○ & $\theta$ & (†) & + \\
\hline Pruneri et al. 2016 (2) & (๑) & + & • & e & ( & $\odot$ \\
\hline Ruan et al. 2018 & (๑) & (-) & $?$ & e & (-) & 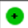 \\
\hline Seo et al. 2013 & \begin{tabular}{|c|}
+ \\
\end{tabular} & (†) & - & $\theta$ & $\odot$ & ๑ \\
\hline Tian et al. 2016 & (๑) & (๑) & - & $\theta$ & (-) & (†) \\
\hline Urru et al. 2018 & ๑) & $\odot$ & e & 3 & ๑) & $\oplus$ \\
\hline West et al. 2013 & - & $\oplus$ & $?$ & e & (๑) & (क) \\
\hline Yeong et al. 2017 & (4) & + & \begin{tabular}{|l|l}
$?$ \\
\end{tabular} & $\theta$ & (๑) & + \\
\hline
\end{tabular}

B

Fig. 5 Risk of bias assessment at the study level. a Risk of bias graph: review authors' judgements about each risk of bias item presented as percentages across all included full reported studies $(n=37)$. b Risk of bias summary: review authors' judgements about each risk of bias item for each included study 

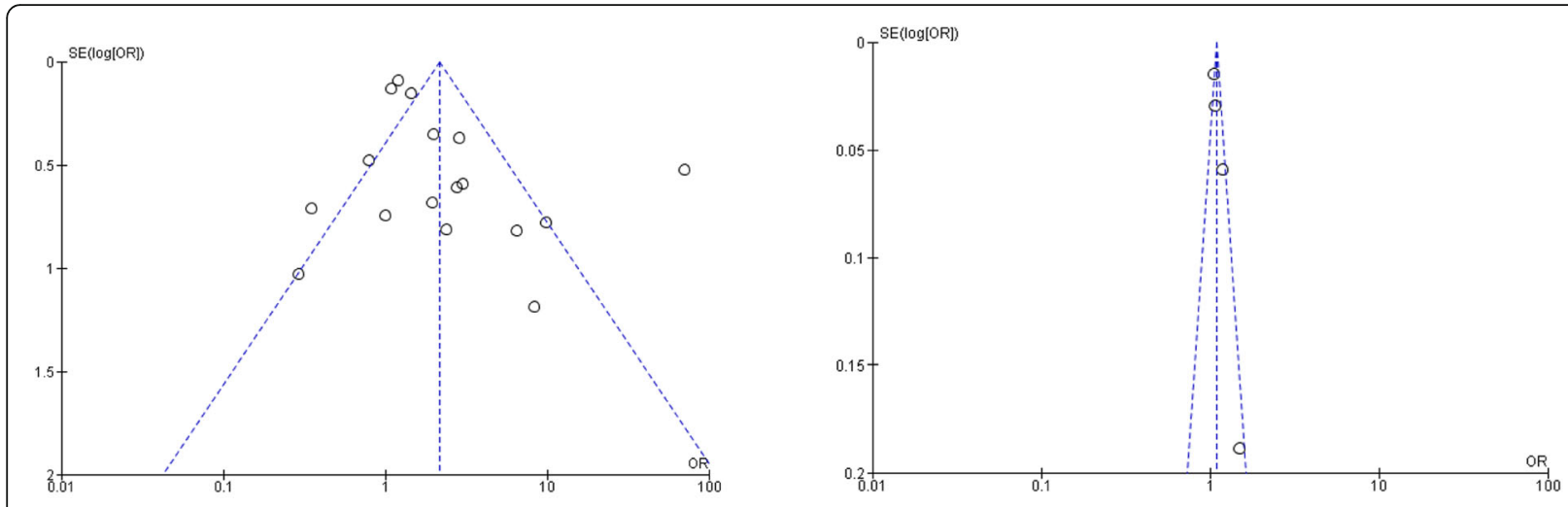

A

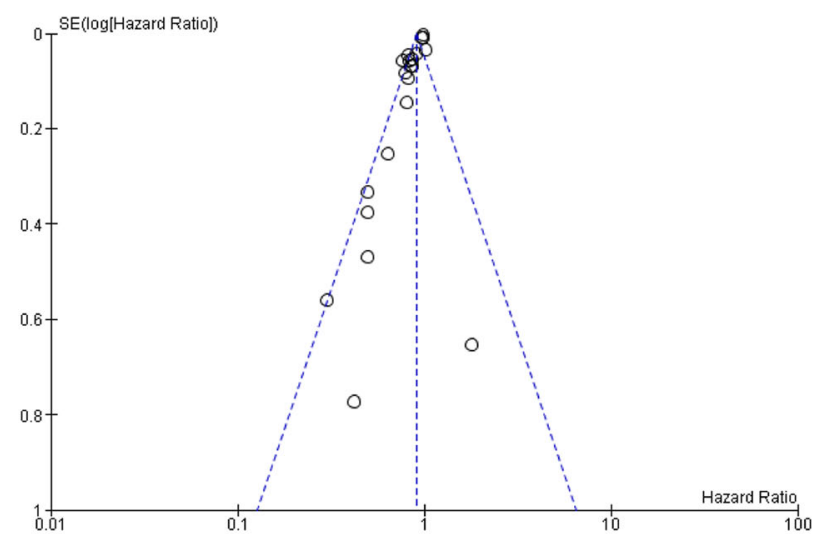

C

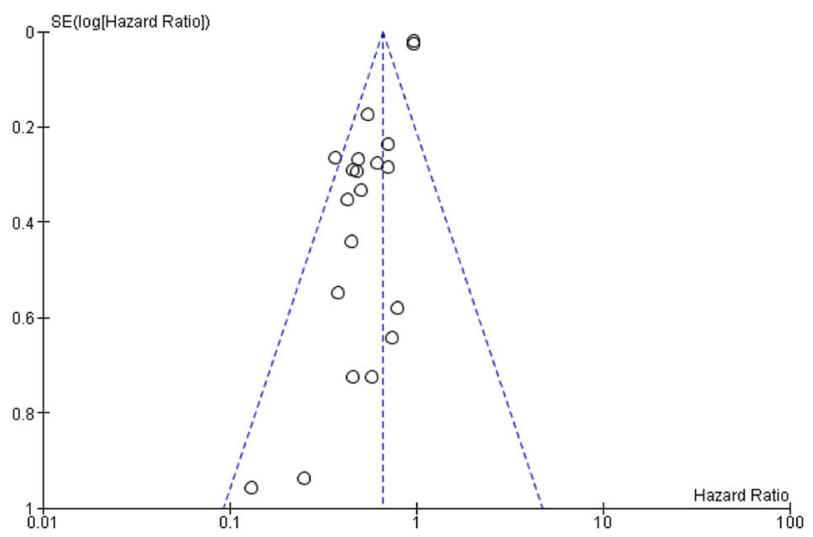

E
B

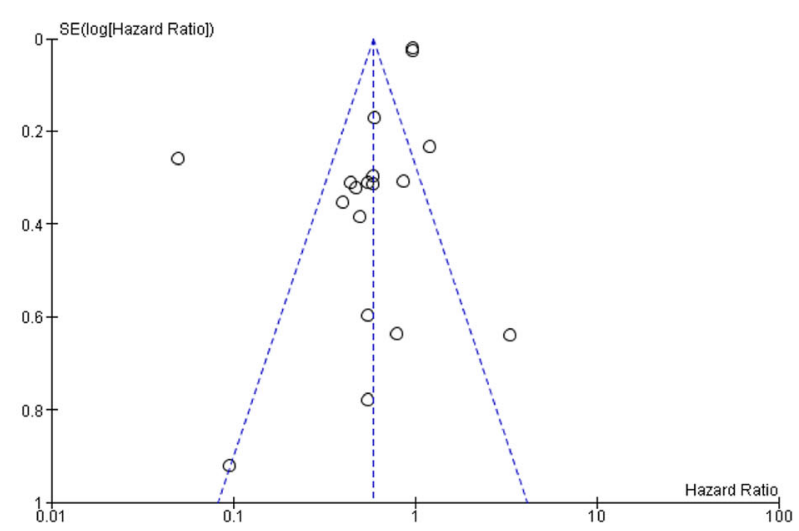

D

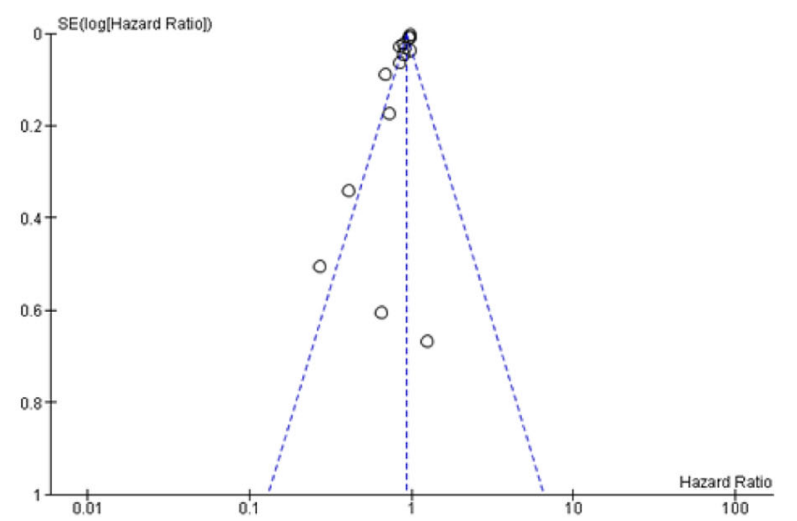

F

Fig. 6 Funnel plot analysis of potential publication bias. a High tumor-infiltrating lymphocytes (TILs) vs. low TILs for pathological complete response (pCR). b Continuous TILs (10\% increase) for pCR. c High TILs vs. low TILs for overall survival (OS). d Continuous TILs for OS. e High TILs vs. low TILs for disease-free survival (DFS). $\mathbf{f}$ Continuous TILs for DFS 
bias related to missing data, TIL measurement, and confounding controls. Next, the variation in the definition of high/low TIL level, and the timeline(s) used for PFS and OS among the included studies can affect the accuracy of the results.

\section{Conclusions}

TNBC with higher levels of TILs showed better shortterm and long-term prognoses. High levels of specific phenotypes of TILs $\left(\mathrm{CD}^{+}, \mathrm{CD}^{+}\right.$, and $\left.\mathrm{FOXP}^{+}\right)$could positively predict the long-term prognosis for TNBC.

\section{Supplementary information}

Supplementary information accompanies this paper at https://doi.org/10. 1186/s12885-020-6668-z.

Additional file 1. Literature search strategy. For additional file1, the content is the search strategies of EMBASE and MEDLINE. For additional file1, the content is the data extraction details of all included articles.

Additional file 2. The data extraction details for the included articles.

\section{Abbreviations}

CD: Cluster of differentiation; Cl: Confidence intervals; DFS: Disease-free survival; ER: Estrogen receptor; FBP3: Forkhead box P3; HER2: Human epidermal growth factor receptor 2; HR: Hazard ratios; IL: Interleukin; OR: Odds ratio; OS: Overall survival; pCR: Pathological complete response; PR: Progesterone receptor; PRISMA: Systematic Reviews and Meta-Analyses: QUIPS: Quality in Prognosis Studies; ROBIN I: Risk Of Bias In Non-randomised Studies - of Interventions; TILs: Tumor-infiltrating lymphocytes; TNBC: Triplenegative breast cancer

\section{Acknowledgements}

The authors would like to thank all of the involved study investigators for dedicating their time and skills to the completion of this study.

\section{Authors' contributions}

GG carried out the initial background research and drafted the manuscript. GG and ZW acted as independent reviewers in screening literature, extracting data, and assessing the quality of each study. GG, ZZ and XQ helped in developing the manuscript or revising it critically for important intellectual content. The author(s) read and approved the final manuscript.

\section{Funding}

This study was supported by the National Key Technologies R\&D Program (No. 2015BAl13B09) and the Research Foundation of Beijing Friendship Hospital, Capital Medical University (No. YYQDKT2018-11). The funding bodies played no role in the design of the study and collection, analysis, and interpretation of data and in writing the manuscript.

\section{Availability of data and materials}

Not applicable.

\section{Ethics approval and consent to participate}

Not applicable.

\section{Consent for publication}

Not applicable.

\section{Competing interests}

The authors declare that they have no competing interests.
Received: 12 December 2019 Accepted: 21 February 2020

Published online: 04 March 2020

\section{References}

1. Foulkes WD, Smith IE, Reis-Filho JS. Triple-negative breast Cancer. N Engl J Med. 2010;363:1938-48.

2. Isakoff SJ. Triple-negative breast cancer: role of specific chemotherapy agents. Cancer J. 2010;16:53-61.

3. Yu X, Zhang Z, Wang Z, Wu P, Qiu F, Huang J. Prognostic and predictive value of tumor-infiltrating lymphocytes in breast cancer: a systematic review and meta-analysis. Clin Transl Oncol. 2016;18:497-506.

4. Perdiguero EG, Geissmann F. Identifying the infiltrators. Science. 2014;344: $801-2$.

5. Korkaya H, Liu S, Wicha MS. Breast cancer stem cells, cytokine networks, and the tumor microenvironment. J Clin Invest. 2011:121:3804-9.

6. Ibrahim EM, Al-Foheidi ME, Al-Mansour MM, Kazkaz GA. The prognostic value of tumor-infiltrating lymphocytes in triple-negative breast cancer: a meta-analysis. Breast Cancer Res Treat. 2014;148:467-76.

7. Seo A, Lee H, Kim E, Kim H, Jang M, Lee H, et al. Tumour-infiltrating CD8+ lymphocytes as an independent predictive factor for pathological complete response to primary systemic therapy in breast cancer. Br J Cancer. 2013; 109:2705.

8. Liu S, Lachapelle J, Leung S, Gao D, Foulkes WD, Nielsen TO. CD8+ lymphocyte infiltration is an independent favorable prognostic indicator in basal-like breast cancer. Breast Cancer Res. 2012;14:R48.

9. Stanton SE, Disis ML. Clinical significance of tumor-infiltrating lymphocytes in breast cancer. J Immunother Cancer. 2016;4:59.

10. Takenaka M, Seki N, Toh U, Hattori S, Kawahara A, Yamaguchi T, et al. FOXP3 expression in tumor cells and tumor-infiltrating lymphocytes is associated with breast cancer prognosis. Mol Clin Oncol. 2013;1:625-32.

11. Liberati A, Altman DG, Tetzlaff J, Mulrow C, Gotzsche PC, loannidis JP, et al. The PRISMA statement for reporting systematic reviews and meta-analyses of studies that evaluate health care interventions: explanation and elaboration. J Clin Epidemiol. 2009;62:e1-34.

12. Fisher B, Bryant J, Wolmark N, Mamounas E, Brown A, Fisher ER, et al. Effect of preoperative chemotherapy on the outcome of women with operable breast cancer. J Clin Oncol. 1998:16:2672-85.

13. Ovcaricek T, Frkovic S, Matos E, Mozina B, Borstnar S. Triple negative breast cancer-prognostic factors and survival. Radiol Oncol. 2011:45:46-52.

14. Sterne JA, Hernan MA, Reeves BC, Savovic J, Berkman ND, Viswanathan M, et al. ROBINS-l: a tool for assessing risk of bias in non-randomised studies of interventions. Bmj. 2016;355:i4919.

15. Hayden JA, van der Windt DA, Cartwright JL, Cote P, Bombardier C. Assessing bias in studies of prognostic factors. Ann Intern Med. 2013;158: 280-6.

16. Manager R. Version 5.0. The Nordic Cochrane Centre. Denmark: The Cochrane Collaboration Copenhagen; 2008.

17. DerSimonian R, Laird N. Meta-analysis in clinical trials. Control Clin Trials. 1986;7:177-88.

18. Adams S, Gray RJ, Demaria S, Goldstein L, Perez EA, Shulman LN, et al. Prognostic value of tumor-infiltrating lymphocytes in triple-negative breast cancers from two phase III randomized adjuvant breast cancer trials: ECOG 2197 and ECOG 1199. J Clin Oncol. 2014;32:2959-66.

19. AiErken N, Shi HJ, Zhou Y, Shao N, Zhang J, Shi Y, et al. High PD-L1 expression is closely associated with tumor-infiltrating lymphocytes and leads to good clinical outcomes in Chinese triple negative breast Cancer patients. Int J Biol Sci. 2017;13:1172-9.

20. Althobiti M, Aleskandarany MA, Joseph C, Toss M, Mongan N, Diez-Rodriquez $M$, et al. Heterogeneity of tumour-infiltrating lymphocytes in breast cancer and its prognostic significance. Histopathology. 2018;73:887-96.

21. Asano Y, Kashiwagi S, Goto W, Takada K, Takahashi K, Hatano T, et al. Prediction of treatment response to Neoadjuvant chemotherapy in breast Cancer by subtype using tumor-infiltrating lymphocytes. Anticancer Res. 2018:38:2311-21.

22. Byun KD, Hwang HJ, Park KJ, Kim MC, Cho SH, Ju MH, et al. T-cell immunoglobulin mucin 3 expression on tumor infiltrating lymphocytes as a positive prognosticator in triple-negative breast cancer. J Breast Cancer. 2018;21:406-14.

23. Cerbelli B, Pernazza A, Botticelli A, Fortunato L, Monti M, Sciattella P, et al. PD-L1 Expression in TNBC: A Predictive Biomarker of Response to 
Neoadjuvant Chemotherapy? Biomed Res Int. 2017;2017:1750925 (no pagination).

24. Denkert C, von Minckwitz G, Brase JC, Sinn BV, Gade S, Kronenwett R, et al. Tumor-infiltrating lymphocytes and response to neoadjuvant chemotherapy with or without carboplatin in human epidermal growth factor receptor 2positive and triple-negative primary breast cancers. J Clin Oncol. 2015;33: 983-91.

25. Denkert C, von Minckwitz G, Darb-Esfahani S, Lederer B, Heppner Bl, Weber $\mathrm{KE}$, et al. Tumour-infiltrating lymphocytes and prognosis in different subtypes of breast cancer: a pooled analysis of 3771 patients treated with neoadjuvant therapy. Lancet Oncol. 2018;19:40-50.

26. Dieci MV, Criscitiello C, Goubar A, Viale G, Conte P, Guarneri V, et al. Prognostic value of tumor-infiltrating lymphocytes on residual disease after primary chemotherapy for triple-negative breast cancer: a retrospective multicenter study. Ann Oncol. 2014;25:611-8.

27. Dieci MV, Mathieu MC, Guarneri V, Conte P, Delaloge S, Andre F, et al. Prognostic and predictive value of tumor-infiltrating lymphocytes in two phase III randomized adjuvant breast cancer trials. Ann Oncol. 2015;26: 1698-704.

28. Galvez M, Castaneda CA, Sanchez J, Castillo M, Rebaza LP, Calderon G, et al. Clinicopathological predictors of long-term benefit in breast cancer treated with neoadjuvant chemotherapy. World J Clin Oncol. 2018;9:33-41.

29. Goto W, Kashiwagi S, Asano Y, Takada K, Takahashi K, Hatano T, et al. Predictive value of improvement in the immune tumour microenvironment in patients with breast cancer treated with neoadjuvant chemotherapy. ESMO Open. 2018;3(6):e000305 (no pagination).

30. Herrero-Vicent C, Guerrero A, Gavila J, Gozalbo F, Hernandez A, Sandiego S, et al. Predictive and prognostic impact of tumour-infiltrating lymphocytes in triple-negative breast cancer treated with neoadjuvant chemotherapy. Ecancermedicalscience. 2017;11:759 (no pagination).

31. Hida Al, Sagara Y, Yotsumoto D, Kanemitsu S, Kawano J, Baba S, et al. Prognostic and predictive impacts of tumor-infiltrating lymphocytes differ between triple-negative and HER2-positive breast cancers treated with standard systemic therapies. Breast Cancer Res Treat. 2016;158:1-9.

32. Jang N, Kwon HJ, Park MH, Kang SH, Bae YK. Prognostic value of tumorinfiltrating lymphocyte density assessed using a standardized method based on molecular subtypes and adjuvant chemotherapy in invasive breast Cancer. Ann Surg Oncol. 2018;25:937-46.

33. Kim JY, Heo SH, Choi SK, Song IH, Park IA, Kim YA, et al. Glutaminase expression is a poor prognostic factor in node-positive triple-negative breast cancer patients with a high level of tumor-infiltrating lymphocytes. Virchows Arch. 2017:470:381-9.

34. Krishnamurti U, Wetherilt CS, Yang J, Peng L, Li X. Tumor-infiltrating lymphocytes are significantly associated with better overall survival and disease-free survival in triple-negative but not estrogen receptor-positive breast cancers. Hum Pathol. 2017;64:7-12.

35. Lee HJ, Park IA, Song IH, Shin SJ, Kim JY, Yu JH, et al. Tertiary lymphoid structures: prognostic significance and relationship with tumour-infiltrating lymphocytes in triple-negative breast cancer. J Clin Pathol. 2016;69:422-30.

36. Leon-Ferre RA, Polley MY, Liu H, Gilbert JA, Cafourek V, Hillman DW, et al. Impact of histopathology, tumor-infiltrating lymphocytes, and adjuvant chemotherapy on prognosis of triple-negative breast cancer. Breast Cancer Res Treat. 2018;167:89-99.

37. Li XX, Wetherilt CS, Krishnamurti U, Yang J, Ma YM, Styblo TM, et al. Stromal PD-L1 expression is associated with better disease-free survival in triplenegative breast Cancer. Am J Clin Pathol. 2016;146:496-502.

38. Loi S, Michiels S, Salgado R, Sirtaine N, Jose V, Fumagalli D, et al. Tumor infiltrating lymphocytes are prognostic in triple negative breast cancer and predictive for trastuzumab benefit in early breast cancer: results from the FinHER trial. Ann Oncol. 2014;25:1544-50.

39. Luen SJ, Salgado R, Dieci MV, Vingiani A, Curigliano G, Gould RE, et al. Prognostic implications of residual disease tumor-infiltrating lymphocytes and residual cancer burden in triple-negative breast cancer patients after neoadjuvant chemotherapy. Ann Oncol. 2019;30:236-42.

40. Matsumoto H, Thike AA, Li HH, Yeong J, Koo SL, Dent RA, et al. Increased CD4 and CD8-positive T cell infiltrate signifies good prognosis in a subset of triple-negative breast cancer. Breast Cancer Res Treat. 2016;156:237-47.

41. McIntire PJ, Irshaid L, Liu YF, Chen ZM, Menken F, Nowak E, et al. Hot Spot and Whole-Tumor Enumeration of CD8(+) Tumor-Infiltrating Lymphocytes Utilizing Digital Image Analysis Is Prognostic in Triple-Negative Breast Cancer. Clin Breast Cancer. 2018;18:451.
42. Miyashita M, Sasano H, Tamaki K, Chan M, Hirakawa H, Suzuki A, et al. Tumor-infiltrating CD8+ and FOXP3+ lymphocytes in triple-negative breast cancer: its correlation with pathological complete response to neoadjuvant chemotherapy. Breast Cancer Res Treat. 2014;148:525-34.

43. Mori H, Kubo M, Yamaguchi R, Nishimura R, Osako T, Arima N, et al. The combination of PD-L1 expression and decreased tumor-infiltrating lymphocytes is associated with a poor prognosis in triple-negative breast cancer. Oncotarget. 2017;8:15584-92.

44. O'Loughlin M, Andreu X, Bianchi S, Chemielik E, Cordoba A, Cserni G, et al. Reproducibility and predictive value of scoring stromal tumour infiltrating lymphocytes in triple-negative breast cancer: a multi-institutional study. Breast Cancer Res Treat. 2018;171:1-9.

45. Ono M, Tsuda H, Shimizu C, Yamamoto S, Shibata T, Yamamoto H, et al. Tumor-infiltrating lymphocytes are correlated with response to neoadjuvant chemotherapy in triple-negative breast cancer. Breast Cancer Res Treat. 2012;132:793-805

46. Park HS, Heo I, Kim JY, Kim S, Nam S, Park S, et al. No effect of tumorinfiltrating lymphocytes (TILs) on prognosis in patients with early triplenegative breast cancer: validation of recommendations by the international TILs working group 2014. J Surg Oncol. 2016;114:17-21.

47. Pruneri G, Gray KP, Vingiani A, Viale G, Curigliano G, Criscitiello C, et al. Tumor-infiltrating lymphocytes (TILs) are a powerful prognostic marker in patients with triple-negative breast cancer enrolled in the IBCSG phase III randomized clinical trial 22-00. Breast Cancer Res Treat. 2016;158:323-31.

48. Pruneri G, Vingiani A, Bagnardi V, Rotmensz N, De Rose A, Palazzo A, et al. Clinical validity of tumor-infiltrating lymphocytes analysis in patients with triple-negative breast cancer. Ann Oncol. 2016;27:249-56.

49. Ruan M, Tian T, Rao J, Xu X, Yu B, Yang W, et al. Predictive value of tumorinfiltrating lymphocytes to pathological complete response in neoadjuvant treated triple-negative breast cancers. Diagn Pathol. 2018;13:66.

50. Tian T, Ruan M, Yang W, Shui R. Evaluation of the prognostic value of tumor-infiltrating lymphocytes in triple-negative breast cancers. Oncotarget. 2016;7:44395-405

51. Urru SAM, Gallus S, Bosetti C, Moi T, Medda R, Sollai E, et al. Clinical and pathological factors influencing survival in a large cohort of triple-negative breast cancer patients. BMC Cancer. 2018;18:11.

52. West N, Kost S, Martin S, Milne K, Deleeuw R, Nelson B, et al. Tumourinfiltrating FOXP3+ lymphocytes are associated with cytotoxic immune responses and good clinical outcome in oestrogen receptor-negative breast cancer. Br J Cancer. 2013;108:155.

53. Yeong J, Thike AA, Lim JCT, Lee B, Li HH, Wong SC, et al. Higher densities of Foxp3(+) regulatory $T$ cells are associated with better prognosis in triplenegative breast cancer. Breast Cancer Res Treat. 2017;163:21-35.

54. Demaria S, Volm MD, Shapiro RL, Yee HT, Oratz R, Formenti SC, et al. Development of tumor-infiltrating lymphocytes in breast cancer after neoadjuvant paclitaxel chemotherapy. Clin Cancer Res. 2001;7:3025-30.

55. Liu S, Duan X, Xu L, Xin L, Cheng Y, Liu Q, et al. Optimal threshold for stromal tumor-infiltrating lymphocytes: its predictive and prognostic value in HER2-positive breast cancer treated with trastuzumab-based neoadjuvant chemotherapy. Breast Cancer Res Treat. 2015;154:239-49.

56. West NR, Milne K, Truong PT, Macpherson N, Nelson BH, Watson PH. Tumorinfiltrating lymphocytes predict response to anthracycline-based chemotherapy in estrogen receptor-negative breast cancer. Breast Cancer Res. 2011;13:R126.

57. Mao Y, Qu Q, Chen X, Huang O, Wu J, Shen K. The prognostic value of tumor-infiltrating lymphocytes in breast cancer: a systematic review and meta-analysis. PLoS One. 2016;11:e0152500.

58. Mao Y, Qu Q, Zhang Y, Liu J, Shen K. Tumor infiltrating lymphocytes (TIL) to predict response to neoadjuvant chemotherapy in breast cancer: a systemic review and meta-analysis. J Clin Oncol Conf. 2014;32:1.

59. Carbognin L, Pilotto S, Nortilli R, Brunelli M, Nottegar A, Sperduti I, et al. Predictive and prognostic role of tumor-infiltrating lymphocytes for early breast Cancer according to disease subtypes: sensitivity analysis of randomized trials in adjuvant and Neoadjuvant setting. Oncologist. 2016;21: 283-91.

\section{Publisher's Note}

Springer Nature remains neutral with regard to jurisdictional claims in published maps and institutional affiliations. 